Chinese Journal of Urban and Environmental Studies

Vol. 6, No. 1 (2018) 1850003 (11 pages)

(C) World Scientific Publishing Company and

Social Sciences Academic Press (China)

DOI: $10.1142 / \mathrm{S} 2345748118500033$

\title{
Assessment of Agricultural Vulnerability to Floods in Shanghai by the DEA Method
}

\author{
SHI Yong \\ School of Tourism Management, Zhengzhou University \\ No. 100 Science Avenue, Zhengzhou, \\ Henan Province 450001, China \\ yongshi@zzu.edu.cn
}

\begin{abstract}
In recent years, as the international community pays increasing attention to disaster prevention and reduction, study on vulnerability has become a new focus in the science of disaster, and it gradually becomes a consideration in strategy-making for sustainable social development. Understanding of vulnerability has become a prerequisite for grasping the nature of disasters, and it is also an area where humans can make a difference in disaster prevention and mitigation. Based on historical disasters and the concepts of vulnerability, this study applies the CCR model, one of the most basic Data Envelopment Analysis (DEA) models, to analyze the pattern of variation regarding agricultural vulnerability to floods in Shanghai suburban areas. The results prove the following: chronologically, the overall vulnerability degrees of Shanghai suburbs listed in the descending order are $1991>1983>1984>1981>1985>1979>1986>1990>1980>$ $1989>1987>1988$; spatially, based on the averages recorded in 2013, the vulnerability levels of Shanghai suburban districts are Nanhui $>$ Jinshan $>$ Songjiang $>$ Baoshan $>$ Qingpu $>$ Pudong $>$ Jiading $>$ Fengxian. The results are basically consistent with the fact. Based on the characteristics of each district's vulnerability to floods, some suggestions for flood prevention and mitigation are provided. The assessment models of flood vulnerability are simple and can be used for vulnerability analysis of natural disasters at regional or national levels. The assessment method adopted in this paper contributes to a deeper understanding of agricultural vulnerability to floods in Shanghai and provides a scientific base for the decision-making of related departments.
\end{abstract}

Keywords: Shanghai; agriculture; flood; vulnerability; DEA.

\section{Introduction}

Floods, one the most frequently-happening natural disasters in the world, seriously affect people's lives and productivity, causing extensive economic loss and serious damages to people, property and the environment. China is one of the countries most afflicted with frequent and severe floods. Owing to global warming and sea-level rising, the influence of floods on coastal cities is becoming more and more significant (Shi, 2010). The flood risks, including the likelihood of occurrence and potential loss to social systems, have been increasing constantly.

Early studies of floods generally focused on understanding the physical processes, spatial distributions and patterns and, to some extent, the impacts of events and measures for mitigation. They were mainly descriptive, rather than analytical, and placed the blame 
for catastrophe firmly on nature instead of human activities, oversimplifying them as "hazards determinism". With further studies, people gradually recognized that natural hazard impacts are the joint product of stress and exposure on the one hand and fragility and vulnerability on the other hand (Blaikie et al., 1994). Natural hazards may exert significantly different impacts on people and places, often not only depending on the severity of the hazard, but also on the physical attributes and the socio-economic characteristics of a locality. In order to remedy the deficiencies in early studies, a new concept of vulnerability was proposed to address natural hazard-related issues.

There is no standard definition for disaster vulnerability. The concept of vulnerability to natural hazards was formulated by the United Nations (UNDRO, 1991) as the degree of loss as a result of potential hazard in a given region. Vulnerability is defined as the asymmetric response of disaster occurrences to hazardous events (Joseph, 2012). It mainly emphasizes the resilience, response and recovery ability of social and economic systems impacted (Shi et al., 2011), and it is a key link between hazards and risks. Vulnerability is recognized as a propensity to suffer adverse consequences when crops are threatened (Blaikie et al., 1994; McCarthy et al., 2001; UNISDR, 2002; Turner et al., 2003a,b). More specifically, in agricultural researches, vulnerability assessment attempts to calculate the loss or potential loss of crops or agricultural systems in order to identify factors causing vulnerability (Wilhelmi and Wilhite, 2002; Zhang et al., 2013a,b).

In vulnerability researches, there are several qualitative and quantitative approaches to vulnerability assessment. Qualitative methods depend on expert opinions. Being partly subjective, results of these approaches vary based on the knowledge of experts. Quantitative methods include data assessment on historical disasters, multi-index evaluation method, and curve-based (vulnerability curve) assessment on hazard loss (Wang et al., 2013). At present, the multi-index evaluation method is the main method to assess vulnerability to natural disasters (Pelling, 2004; Peduzzi, 2006; Dilley et al., 2005; Bollin et al., 2006; Cardona, 2005; Davidson and Shah, 1997; Peduzzi et al., 2005; Peduzzi, 2006). But, these methods require a calculation of the weights of sub-indices. Various methods such as the analytical hierarchy process (AHP), the fuzzy comprehensive evaluation and the Delphi method have been developed to calculate the weights. The values of weightings to a great extent depend upon arbitrary decisions, thus it makes the evaluation results less objective and thus undermines the public confidence.

In order to minimize the influence of subjective factors and improve the objectivity of evaluation results, this paper introduces the Data Envelopment Analysis (DEA) method for assessing agricultural vulnerability to floods.

\section{Materials and Methods}

\subsection{The study area}

Shanghai, located at $31^{\circ} 41^{\prime}$ north latitude and $121^{\circ} 29^{\prime}$ east longitude, is one of the largest seaports in the world and a major industrial and commercial center of the People's Republic of China. The suburbs in Shanghai includes nine districts, respectively, Chongming, Baoshan, Jiading, Qingpu, Minhang, Songjiang, Jinshan, Fengxian and Pudong New Area (Fig. 1). 


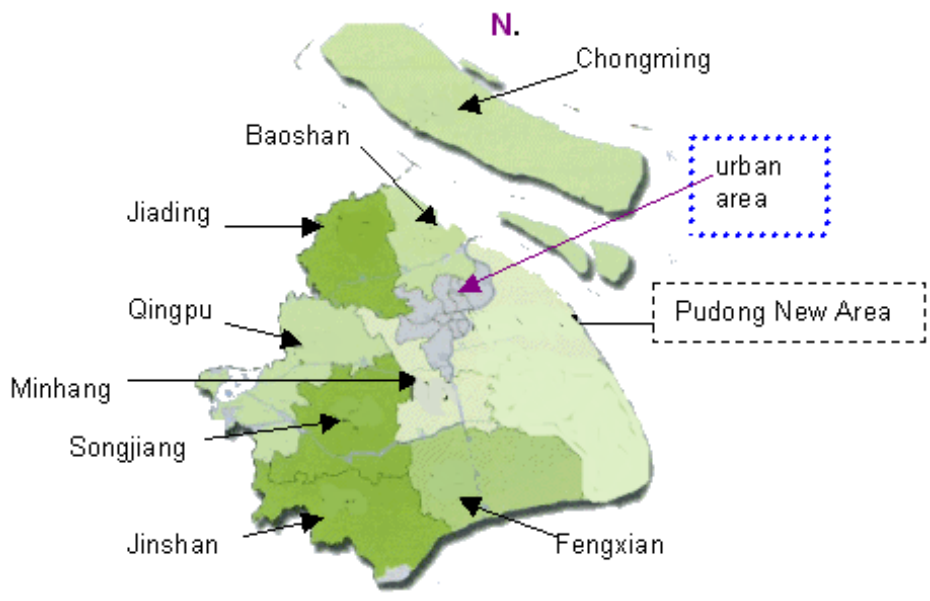

Source: Made by the author.

Fig. 1. Suburban areas of Shanghai.

Shanghai, both urban and suburban parts combined, covers a total area of $6,340.5 \mathrm{~km}^{2}$ while its suburban part covers an area of $6,000 \mathrm{~km}^{2}$.

The city of Shanghai is south to the Yangtze River, west to the East China Sea and north to the Hangzhou bay. The Huangpu River meanders across Shanghai, providing adequate water resource for it.

This city enjoys fertile soil and convenient transportation. Nevertheless, Shanghai is located at an altitude lower than the middle tidal level of the Huangpu River, therefore, the groundwater cannot discharge freely. The special location and low altitude make floods a big concern for this city. As a densely populated economic center, different kinds of natural hazard factors and anthropic factors interact and affect each other. Consequently, they have adverse effects on social development.

Floods in Shanghai include those incurred by rainstorms and others caused by tides from nearby rivers or seas, leading to huge economic losses to the big international city. In urban areas, floods can usually be attributed to rainstorms. Rainstorms cause water accumulation on roads and thus interrupt traffic seriously, while frequent water leaks in residences inundate private properties. In suburbs, floods mainly lead to crop yield reduction, because the soil is too wet to support crop growth should rainstorms last for a long period of time. Ironically, because of the fine soil particles, soil in Shanghai can hold much water. As a consequence, plant roots cannot breathe as usual and huge economic loss is inevitable.

\subsection{Theoretical basis}

Agricultural vulnerability in this study is defined as the potential maximum loss of crops due to floods in a given region during a given time period. This paper considers agriculture environment as a system with sown area being the input, affected area being the output, and 
vulnerability of this system as the state variable. In general, worst-hit area, lightly damaged area and flooded area indicate higher agricultural vulnerability to floods.

When catastrophes come, it is not necessary for hazard-bearing bodies to suffer a complete loss. Vulnerability, in other words, is the measurement of damage done to hazardbearing bodies. It is a quantitative characteristic of hazard-bearing bodies when they are damaged or suffer losses when natural hazards come at certain social, political, economic and cultural contexts. It reflects how badly our society is affected and threatened by natural disasters. Therefore, it is an important component in risk assessment.

In history, vulnerability to natural disasters is regarded as a result. It means the level of damage done to hazard-bearing bodies when facing disasters. The difference among hazard-bearing bodies lies in the different damage level they suffer when being exposed to the same catastrophe.

Based on the historical data, vulnerability to disasters can be seen as a negative production activity. If it is demonstrated with an input-output model (see Fig. 2), "input" includes grain acreage, population, economy, "output" refers to the affected area, injured population and economic losses, and vulnerability is the input-output efficiency. When the efficiency is greater, vulnerability is greater. Vulnerability of hazard-bearing bodies to disasters takes different forms, just as shown in Fig. 2. Among sown areas of the same size, vulnerability grows in line with the coverage of affected areas, assuming that those sown areas are hit by hazards of the same intensity.

Vulnerability is determined by the physical sensitiveness of hazard-bearing bodies in the disaster system. For instance, various crops have different resistance against disasters. Vulnerability is also closely linked to social and economic environment. Vulnerability to historical disasters is determined based on their consequences. It has both physical and socio-economic dimensions. Additionally, due to the complicated formation of vulnerability to natural disasters, this input-output decision unit to assess the efficiency, namely the DEA method, is very suitable. One only needs to constantly evaluate and compare the vulnerability in every decision unit based on the input-output model. It is not necessary to set functional relations, parameters or weights of different factors. In this way, one does not

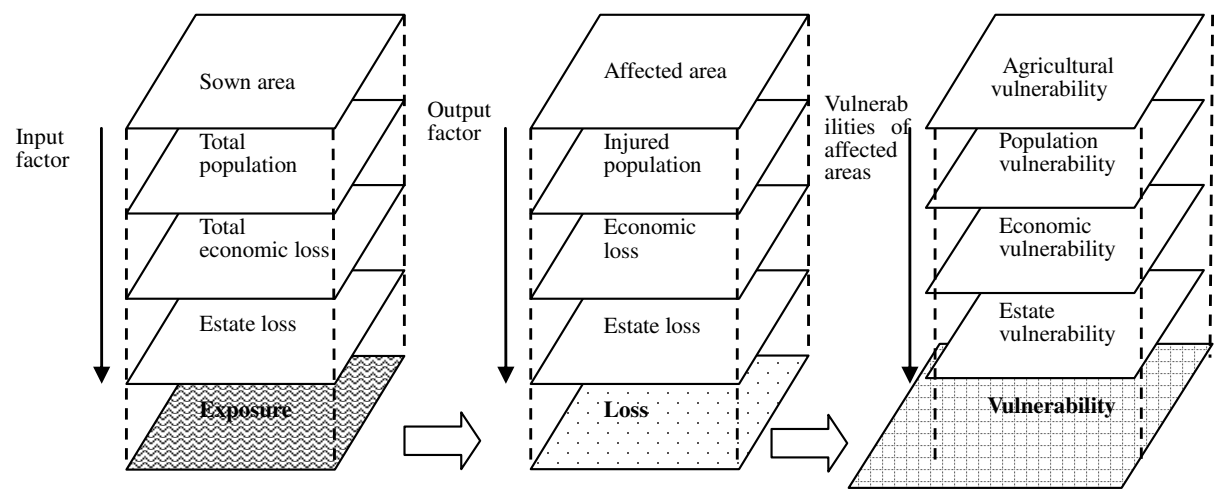

Source: Made by the author.

Fig. 2. Input and output analysis model of vulnerability to natural disasters. 
have to go through the trouble of taking the root causes or the formation process of vulnerability into consideration. Valid assessment can be made with the help of explicit indicators.

\subsection{Research method}

The DEA method originated from a paper titled "The Measurement of Productive Efficiency" (Wu, 2007), which was first published by Farrell. It is a non-parametric estimation method measuring the input-output efficiency of various decision-making units (DMUs). Mathematical programming is used in this method to identify the boundary formed by the most efficient input-output combination points. This method projects all assessed units, namely DMU into geometry pictures. Based on the factual data and mathematical programming, the efficient frontier can be obtained. Thus, the location of each input-output combination determines its efficiency. Generally speaking, DMUs that fall on the boundary indicate the most efficient input-output combination and they are given a key performance indicator (KPI) of 1. Combinations beyond the efficient frontier are seen as inefficient with KIPs ranging from 0 to 1 . In this case, KPI is produced in reference to particular efficient points (Wang, 2006).

In terms of agricultural existences exposed to natural hazards, there is barely anything humans can do except adjusting the acreage of sown areas. The actual disaster situation is not controllable. Therefore, we choose the input-oriented model to measure vulnerability, which includes the most classic and widely used model in envelopment analysis, namely the CCR model. And that is also the most sophisticated model so far. The working mechanism of the CCR model is as follows.

A production activity can be represented by a set of input and output values. Assuming that there are $n \mathrm{DMU}_{j}(j=1,2, \ldots, n)$, and each DMU has $m$ kinds of inputs and $s$ kinds of outputs, then these DMUs would constitute a multi-index input-output evaluation system. The CCR model puts the input and output factors of DMUs into linear combinations and presents them in mathematical programming models. The ratio of combinations represents the efficiency of DMU. Assuming that the input value of unit $j$ using item $i$ $(i=1,2, \ldots, m)$ is $X_{i j}$, and the output value using item $r$ is $Y_{r j}(r=1,2, \ldots, s)$, and then the efficiency of unit $k$ can be obtained by model (1) as follows:

$$
\operatorname{Max} E_{k}=\frac{\sum_{r=1}^{S} \mu_{r} Y_{r k}}{\sum_{i=1}^{m} \nu_{i} X_{i k}},
$$

s. t.

$$
\begin{aligned}
& \frac{\sum_{r=1}^{S} \mu_{r} Y_{r k}}{\sum_{i=1}^{m} \nu_{i} X_{i k}} \leq 1, \quad j=1, \ldots, n, \\
& \mu_{r} \geq \varepsilon>0 ; \quad r=1, \ldots, s, \\
& \nu_{i} \geq \varepsilon>0 ; \quad i=1, \ldots, m .
\end{aligned}
$$

In model (1), $\mu_{r}$ and $V_{i}$, respectively, represent the weight of output item NO. $r$ and input item NO. i. $n$ represents the number of DMUs, $M$ represents the number of input 
items, $s$ represents the number of output items and $\varepsilon$ is an extremely small positive number called non-Archimedean number, usually set at $10^{-4}$ or $10^{-6} . Y_{r k}$ represents output value NO. $r$ of DMU NO. $k$, while $X_{i k}$ represents input value NO. $i$ of DMU NO. $k$. $E_{k}$ represents the efficiency value of DMU NO. $k$. Therefore, it can be inferred that DEA in essence calculates the ratio of input and output. The goal of the DEA model is to identify the most favorable-weighted value among the set of feasible solution in order to maximize the efficiency value $\left(E_{k}\right)$ of each DMU.

\section{Assessment of Agricultural Vulnerability to Floods in Shanghai}

Theoretically, casualty, economic loss and agricultural disaster area, etc. are all part of the disaster situation. However, due to the limited data access, this study only takes the sown areas of the nine suburban districts from 1979 to 1991 as the input items and the worst-hit areas, lightly damaged areas and flooded areas (in reference to The Flood and Drought Disaster of Shanghai (Yuan, 1999)) of corresponding years as the output items to assess vulnerability to floods.

\subsection{Preparation for evaluation}

First, the input items and output items need to be tested to verify whether they accord with the expansionary assumption that output does not decrease when input increases. In order to analyze and test the correlation, a correlation matrix is built.

The input and output values from each district during 1979-1991 are added together and verified for Pearson's Correlation using the SPSS program (Table 1). The result is as follows: no negative correlation is identified among the input and output values, and the correlation between lightly damaged area and sown area is weak. But, the lightly damaged areas are taken into account because light disasters happen more frequently than heavy disasters and flooding in Shanghai.

Finally, the input and output values of each district from 1979 to 1991 are added up and put to the correlation test (Table 2). No negative correlation is found among the input and output values of each year. Although the negative correlation of flooded area represents negative correlation, it is included as a measure indicator to ensure the inclusiveness of the analysis because the flooded area still represents a marked correlation in the first correlation verification on different districts. Therefore, one input item and three output items are all included in the benefit analysis.

Table 1. Correlation analysis of input-output in each district of Shanghai (0.05 confidence level).

\begin{tabular}{|c|c|c|c|}
\hline Input & Worst-hit area (acre) & Lightly damaged area (acre) & Flooded area (acre) \\
\hline & 0.307 & 0.12 & 0.708 \\
\hline
\end{tabular}

Source: Made by the author according to Yuan Zhilun's Flood and Drought Disasters in Shanghai (Yuan, 1999) and the DEA method. 
Table 2. Correlation analysis of input-output of Shanghai during 1979-1991 (0.05 confidence level).

\begin{tabular}{lccc}
\hline Input & Worst-hit area (acre) & Lightly damaged area (acre) & Flooded area (acre) \\
\hline Sown area (acre) & 0.874 & 0.587 & -0.329 \\
\hline
\end{tabular}

Source: Made by the author according to Yuan Zhilun's Flood and Drought Disasters in Shanghai (Yuan, 1999) and the DEA method.

It is noted that this study is perfectly valid, because it includes nine districts, with one input item and three output items, meeting the requirement that the number of assessed DMUs should be at least twice the sum of the input items and output items and thus ensuring the credibility of the findings (Zhong, 2006).

\subsection{Evaluation}

There are a number of statistical software performing the DEA model, such as Lindo, Frontier analysis, EMS, Matlab, etc. This research employs MYDEA, an envelope analysis software developed in 2009 by Peking University and Beijing University of Science and Technology.

In order to compare vulnerability of different regions in different years, this study conducts input-output benefit analyses on 117 DMUs based on disaster data of nine districts during 13 years (1979-1991) in order to eliminate incidental factors and improve accuracy as well as to facilitate dynamic assessment and comparative analysis of vulnerability to floods in various regions.

According to the analysis, there are four occasions when the vulnerability value is 1 , respectively, Jinshan District in 1983, Nanhui District in 1981 and 1984 and Chongming District in 1991 (see Fig. 3). In addition, the total annual vulnerability value can be obtained by adding up the vulnerability value of each district in every year. The vulnerability values of each region during the 13 years are averaged to obtain the average level of vulnerability of the region.

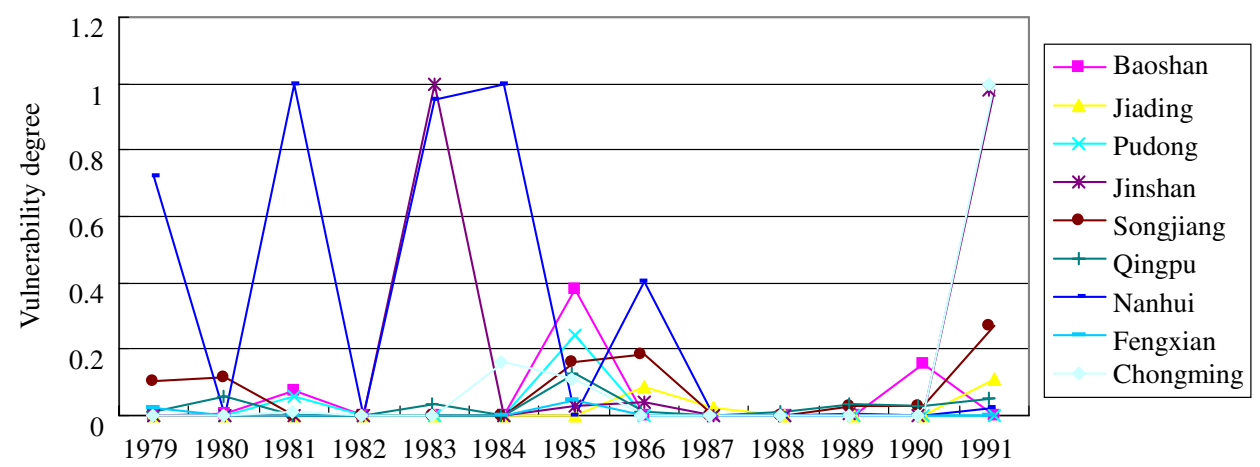

Source: Made by the author according to Yuan Zhilun's Flood and Drought Disasters in Shanghai (Yuan, 1999) and the DEA method.

Fig. 3. Temporal and spatial distribution of agriculture vulnerability of each district in Shanghai. 
Table 3. Classification of districts based on agricultural vulnerability to floods.

\begin{tabular}{cc}
\hline Vulnerability degree & District \\
\hline$\leq 0.1$ & Fengxian (0.005), Jiading (0.017), Pudong (0.023), \\
& Qingpu (0.029), Baoshan (0.047), Songjiang (0.069) \\
$0.1-0.2$ & Chongming (0.100), Jinshan (0.158) \\
$0.2-0.3$ & Nanhui (0.315) \\
\hline
\end{tabular}

Source: Made by the author according to Yuan Zhilun's Flood and Drought Disasters in Shanghai (Yuan, 1999) and the DEA method.

Chronologically, the overall vulnerability degrees of Shanghai suburbs listed in descending order are $1991>1983>1984>1981>1985>1979>1986>1990>1980$ $>1989>1987>1988$ (1982 is excluded due to the lack of data). Since this study is a comprehensive benefit analysis on 117 DMUs, it can present comparative analysis on vulnerability of different regions in different years.

Spatially, based on averages recorded in 2013, the vulnerability values of Shanghai suburban districts listed in descending order are Nanhui $(0.315)>$ Jinshan $(0.158)>$ Chongming (0.100) > Songjiang (0.069) > Baoshan (0.047) > Qingpu (0.029) > Pudong $(0.023)>$ Jiading $(0.017)>$ Fengxian $(0.005))$. In reference to relevant standard, regions could be placed at three levels as shown in Table 3 .

\subsection{Results}

Based on the frequency, intensity and affected area of floods in Shanghai, districts listed in the descending order of flood risk are as follows: Nanhui $>$ Songjiang $>$ Qingpu $>$ Baoshan $>$ Jinshan $>$ Chongming $>$ Jiading $>$ Pudong $>$ Fengxian $>$ Minhang (Shi, 2010). Results of vulnerability assessment show that agricultural vulnerability to floods in Nanhui District is the dominantly highest of all, which probably can be attributed to the highest flood risk of this district. The high frequency, fierce intensity and large affected area indicate that the impact of floods has far exceeded the human capacity to respond to them. Fengxian, Jiading and Pudong show less vulnerability, a sign that flood is not as threatening to agriculture in these regions. Besides, flood risk and vulnerability of Pudong, Jiading and Fengxian are both low, indicating the close relation between flood risk and vulnerability.

Songjiang has a high flood risk, but its vulnerability to flood is only remarkably high in certain years. On the other hand, its average vulnerability over years is also lower than that of Jinshan and Chongming, whose flood risk, curisouly, is lower than that of Songjiang. By the same token, Jinshan and Chongming also have lower flood risks than Qingpu and Baoshan, but their vulnerability is higher than that of Qingpu and Baoshan. It is therefore inferred that despite the close link between flood risk and vulnerability, and vulnerability usually grows with flood risk, but vulnerability is not totally dependent upon flood risk. Vulnerability depends on not only flood risk, but also on local socio-economic environment as well as measures and consciousness of disaster prevention and mitigation. 


\section{Discussion and Conclusion}

\subsection{Discussion}

The current assessment leads to the delineation of areas with different vulnerability to floods in Shanghai. The nine districts are characterized by risk and vulnerability: low risk and low vulnerability in Fengxian, Jiading and Pudong; high risk and high vulnerability in Nanhui; medium risk and medium vulnerability in Baoshan and Chongming; low risk and high vulnerability in Jinshan; high risk and low vulnerability in Songjiang and Qingpu.

In terms of Songjiang and Qingpu, the high level of hazard results in high flood risk. The frequency, intensity and duration of perturbations affecting the system should be reduced. The key constructions of non-engineering flood control measures for the agriculture in the near future are to achieve the standardization and modernization of flood control work, increase the accuracy of the flood forecasting and manage the flood control works scientifically by using modern science and technology. Particularly, as one of the main structural flood control measures, reservoir plays an important role in national economic development and social stability.

Regarding Nanhui and Jinshan, it is imperative to reduce vulnerability. In other words, the resilience, response and recovery ability of human social and economic system should be strengthened before the agriculture system is impacted by floods, which refer to biotechnical or socio-economic factors that are intrinsic to the agricultural system and interact with external perturbations to amplify or reduce their impacts. The ability of the agriculture system to deal with perturbations and increase the extent of variability that it can cope with is supposed to be enhanced by local government. For example, local government can provide natural, financial, institutional or human resources that the agricultural system can mobilize for coping with constraints and overcoming floods. Both internal and external factors can be used to deal with changeable environments, such as some management practices and institutional frameworks for promoting the resilience, response and recovery ability.

As for Fengxian, Jiading and Pudong, vulnerability to floods and flood risk are both low. But to Baoshan and Chongming, measures to mitigate hazards and vulnerability to floods should be carried out at the same time. One way of reducing the damage caused by floods is to remove agriculture from flood-prone areas, turning them into parks or wilderness areas. Otherwise, flood insurance rate maps that identify areas of future risks should be made to enable local governments to apply zoning regulations to prevent or minimize property damage.

\section{Conclusion}

Through this study, agricultural vulnerability to floods in Shanghai is assessed with the DEA method. The temporal and spatial characteristics of agricultural vulnerability to floods in Shanghai suburban districts are analyzed, verifying the close relation and differentiation between vulnerability and risk based on historical disaster data. This study provides scientific references regarding disaster prevention and mitigation for local government and relevant 
departments. However, the study does have limitations due to a lack of data, such as economic loss, casualties, etc. In addition, it is difficult to delve deep into the formation mechanism of vulnerability only from the perspective of disaster consequences. There is still room for improvement in such regards.

\section{Acknowledgments}

The authors would like to thank A.-Li Sun for helping with the experiment design. The authors are also extremely grateful to Shi-Yuan Xu and Chun Shi for their helpful feedback. This research is supported by the Ministry of Education of Humanities and Social Sciences Project (Grant No. 14YJCZH128) and the National Natural Science Foundation of China (Grant Nos. 41601566, 41771540 and 71603168). Much gratitude also goes to the reviewers of this manuscript for their constructive and useful suggestions.

\section{References}

Blaikie, Piers, Terry Cannon, Ian Davis, and Ben Wisner. 1994. At Risk: Natural Hazards, People's Vulnerability and Disasters. London: Routledge.

Bollin, Christina, and Ria Hidajat. 2006. "Community-Based Disaster Risk Index: Pilot Implementation in Indonesia." In Measuring Vulnerability to Natural Hazards-Towards Disaster Resilient Societies, ed. Jörn Birkmann, pp. 271-289. Tokyo: United Nations University Press.

Cardona, Omar D. 2005. Indicators of Disaster Risk and Risk Management: Program for Latin America and the Caribbean: Summary Report. Washington, DC: IDB Publications.

Davidson, Rachel A., and Haresh C. Shah. 1997. "An Urban Earthquake Disaster Risk Index." The John A. Blume Earthquake Engineering Center Report No. 121.

Dilley, Maxx, World Bank Group, Margaret Arnold, Uwe Deichmann, Robert S. Chen and Arthur L. Lerner-Lam. 2005. Natural Disaster Hotspots: A Global Risk Analysis. Washington DC: The World Bank.

International Strategy for Disaster Reduction of United Nations (UNISDR). 2002. Living With Risk: A Global Review of Disaster Reduction Initiatives. Geneva: United Nations Office for Disaster Risk Reduction.

Joseph, Jacquleen. 2012. "Measuring Vulnerability to Natural Hazards: A Macro Framework." Disasters, 37(2): 185-200.

McCarthy, J., Osvaldo F. Canziani, N. A. Leary, D. J. Dokken, and K. S. White, eds. 2001. Climate Change 2001: Impacts, Adaptation, and Vulnerability, Contribution of Working Group II to the Third Assessment Report of the Intergovernmental Panel on Climate Change. Cambridge: Cambridge University Press.

Pelling, Mark. 2004. Visions of Risk: A Review of International Indicators of Disaster Risk and Its Management. Geneva: UNDP - Bureau for Crisis Prevention and Recovery (BRCP).

Pelling, Mark. 2006. "Review of Global Risk Index Projects: Conclusions for Sub-national and Local Approaches." In Measuring Vulnerability to Natural Hazards: Towards Disaster Resilient Societies, ed. Jörn Birkmann, pp. 151-170. Tokyo: UNU Press.

Peduzzi, Pascal. 2006. "The Disaster Risk Index: Overview of a Quantitative Approach.” In Measuring Vulnerability to Natural Hazards: Towards Disaster Resilient Societies, ed. Jörn Birkmann, pp. 171-181. Tokyo: UNU Press.

Peduzzi, Pascal, Christian Herold, and Quoc-Hy Dao. 2005. "Mapping Disastrous Natural Hazards Using Global Datasets." Natural Hazards, 35(2): 265-289. 
Shi, Yong. 2010. "Research on Vulnerability Assessment of Cities on the Disaster Scenario - A Case Study of Shanghai City.” Ph.D. dissertation, East China Normal University.

Shi, Yong, Shiyuan Xu, Chun Shi, Ali Sun, and Qingliang Zhao. 2011. "A Review of Vulnerability Assessment of Natural Disasters." Journal of Natural Disasters, 20(2): 131-137.

Turner II, Billie Lee, Roger E. Kasperson, Pamela A. Matson, James J. McCarthy, Robert W. Corell, Lindsey Christensen, Noelle Eckley, Jeanne X. Kasperson, Amy Luers, Marybeth L. Martello, Colin Polsky, Alexander Pulsipher, and Andrew Schiller. 2003a. "A Framework for Vulnerability Analysis in Sustainability Science." Proceeding of the National Academy of Sciences USA, 100(14): 8074-8079.

Turner II, Billie Lee, Pamela A. Matson, James J. McCarthy, Robert W. Corell, Lindsey Christensen, Noelle Eckley, Grete K. Hovelsrud-Broda, Jeanne X. Kasperson, Roger E. Kasperson, Amy Luers, Marybeth L. Martello, Svein Mathiesen, Rosamond Naylor, Colin Polsky, Alexander Pulsipher, Andrew Schiller, Henrik Selin, and Nicholas Tyler. 2003b. "Illustrating the Coupled Human-Environment System for Vulnerability Analysis: Three Case Studies." Proceeding of the National Academy of Sciences USA, 100(14): 8080-8085.

Office of the Disaster Relief Coordinator of the United Nations (UNDRO). 1991. Mitigating Natural Disasters: Phenomena, Effects and Options: A Manual for Policy Makers and Planning. New York: United Nations.

Wang, Minhua. 2006. The Research on Supplier Selection Under Supply Chain Management. Journal of China Maritime Business College, 1(2): 177-202.

Wang, Zhiqiang, Fei He, Weihua Fang, and Yongfeng Liao. 2013. "Assessment of Physical Vulnerability to Agricultural Drought in China." Natural Hazards, 67(2): 645-657.

Wilhelmi, Olga V., and Donald A. Wilhite. 2002. "Assessing Vulnerability to Agricultural Drought: A Nebraska Case Study." Natural Hazards, 25(1): 37-58.

Wu, Jiansheng. 2007. "An Analysis of Operating Efficiency for Contracting out Public Off-Street Parking Lots: A Case Study for Taipei City.” Master's dissertation, National Taiwan University.

Yuan, Zhilun. 1999. Flood and Drought Disasters in Shanghai. Nanjing: Hohai University Press.

Zhang Qiang, Mingzhong Xiao, Vijay P. Singh, and Xiaohong Chen. 2013a. "Copula-based Risk Evaluation of Hydrological Droughts in the East River Basin, China." Stochastic Environmental Research and Risk Assessment, 27(6): 1397-1406.

Zhang, Zhao, Pin Wang, Yi Chen, Shuai Zhang, Fulu Tao, and Xiaofei Liu. 2013b. "SpatioTemporal Changes of Agro-Meteorological Disasters for Wheat Production across China Since 1990." Journal of Geographical Sciences, 68(11): 1453-1460.

Zhong, Jialin. 2006. "The Assessment of Vulnerability to Typhoon Disasters in Taiwan Area." Master's diss. Chaoyang University of Technology. 